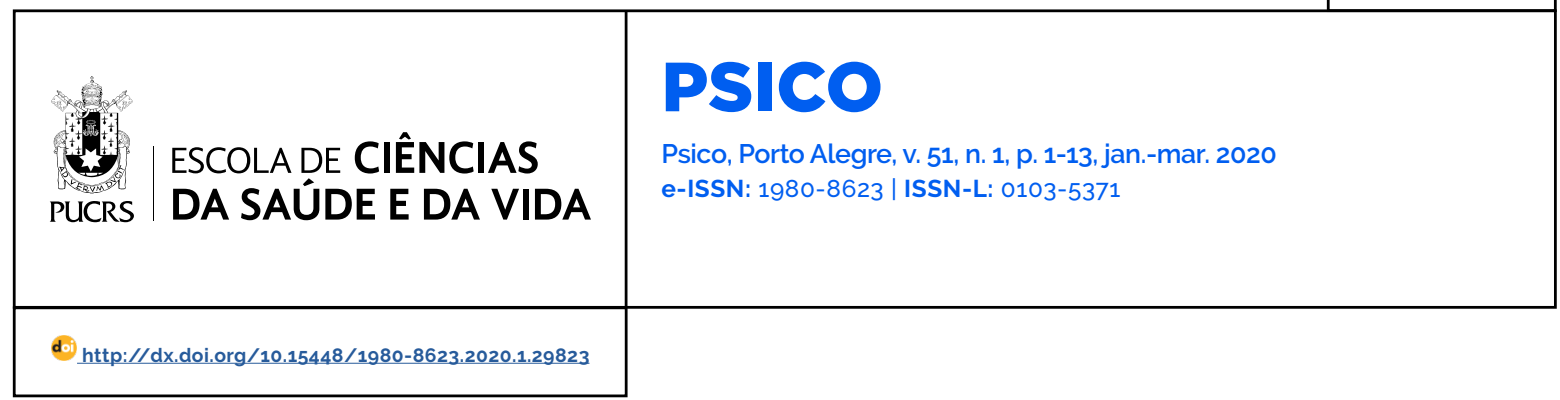

ARTIGOS

\title{
Sistema de cotas para entrada no Ensino Superior: perspectivas de jovens negros de Fortaleza
}

\author{
Affirmative action quotas in Higher Education admissions: perspectives of young black \\ people in Fortaleza \\ Sistema de cuotas para ingreso a la Educación Superior: perspectivas de jóvenes \\ negros de Fortaleza
}

\section{Lívia Lima Gurgel ${ }^{1}$ \\ orcid.org/0000-0003-2095-2415 \\ livialgurgel@gmail.com}

\section{Veriana de Fátima \\ Rodrigues Colaço ${ }^{2}$}

orcid.org/0000-0002-7863-4287

verianac@gmail.com

Recebido em: 26 jan. 2018

Aprovado em: 4 jun. 2019.

Publicado em: $x \times$ XXX. 2020.
Resumo: Em 2013 a Universidade Federal do Ceará inaugurou a Política de Cotas no Estado. Diante disso, objetivou-se analisar a compreensão dos estudantes negros de escolas públicas de Ensino Médio de Fortaleza acerca das implicações do sistema de cotas para eles próprios e para os cursos universitários. Participaram 464 estudantes, a maioria do sexo feminino, com idade entre 14 e 16 anos e que se autodeclararam pardos ou pretos. A partir da Análise de Conteúdo foram examinadas as justificativas dadas pelos estudantes aos itens 09, 12 e 13 do questionário utilizado na pesquisa. Os resultados indicam que os estudantes consideram que há mais possibilidades de ingresso no Ensino Superior, mas poucos apontam mudanças para os cursos universitários. Foram encontradas opiniões contraditórias acerca desse sistema. Articulando contribuições de Foucault e Guatarri, as discussões trouxeram elementos sobre o processo de embranquecimento da sociedade brasileira, o racismo estrutural e o lugar privilegiado do branco na sociedade.

Palavras-chave: sistema de cotas, politicas de ações afirmativas, juventude negra, racismo.

Abstract: In 2013 the Federal University of Ceará inaugurated the affirmative acctions in the State. Following this new reality, the objective was to analyze the understanding of the black students of public high schools in Fortaleza about the implications of the affirmative acctions quota for themselves and for university courses. The sample was characterized by 464 participants, most of them female, between 14 and 16 years old and who declared themselves to be brown or black. Using the Content Analysis we examined the justifications given by the students to items 09, 12 and 13 of the questionnaire used in the research. The results indicate that students consider that there is greater possibility of entering higher education, but few consider changes for the university courses themselves. It has also been observed that there are still many contradictory opinions about this system. Articulating contributions from Foucault and Guatarri, the discussions brought elements about the whitening process of Brazilian society, structural racism and the privileged place of white people in society.

Keywords: quota systems, affirmative action policies, black youth, racism.

Resumen: En 2013 la Universidad Federal del Ceará inauguró la Política de Cuotas en el Estado. A partir de esta nueva realidad, es objetivo fué analizar la comprensión de los estudiantes negros de escuelas públicas de nivel medio de Fortaleza acerca de las implicaciones del sistema de cuotas para ellos mismos y para los cursos universitarios. La muestra se caracterizó por 464 participantes, la mayoría del sexo femenino, con edad entre 14 y 16 años y que se autodeclararon pardos o negros. A partir del Análisis de Contenido se examinaron las justificaciones dadas por los estudiantes a los items 09, 12 y 13 del cuestionario utilizado en la investigación. Los resultados indican que los estudiantes están 
considerando que hay mayores posibilidades de ingreso en la educación superior, pero pocos consideran cambios para los cursos universitarios. También se observó que todavía existen opiniones contradictorias acerca de ese sistema. Articulando contribuciones de Foucault y Guatarri, las discusiones trajeron elementos sobre el proceso de blanqueamiento de la sociedad brasileña, el racismo estructural y el lugar privilegiado de personas blancas en la sociedad.

Palabras clave: sistemas de cuotas, políticas de acciones afirmativas; juventud negra, racismo.

O presente artigo busca relatar, de forma breve, o percurso do movimento negro no Brasil, apresentando o caminho desde as lutas históricas desse movimento até o surgimento das políticas de ações afirmativas no País. Será dada maior ênfase à política de cotas para entrada no Ensino Superior e serão apresentados dados obtidos por meio de uma pesquisa realizada em Fortaleza que se intitulou "Expectativas de futuro de jovens negros do ensino médio de escolas públicas de Fortaleza: implicações da implantação do Sistema de Cotas no Ceará", realizada entre o periodo de 2014 e 2016, e por meio de uma monografia que se originou do supracitado estudo, que teve como título "A percepção de alunos negros do ensino médio público de Fortaleza acerca do sistema de cotas para ingresso no Ensino Superior" e foi concluida em 2016.

O Brasil foi construído a partir da exploração de negros africanos que foram escravizados. É importante que seja realizada uma retrospectiva do processo de escravidão ao qual os negros foram submetidos no País, para que seja possivel refletir sobre as condições desses sujeitos na atual sociedade e por quê, ainda hoje, são necessárias políticas reparatórias para essa parcela da população. Segundo Monteiro (2012), com a chegada dos colonizadores europeus ao Brasil e diante da morte de inúmeros índios que não resistiam à exploração sofrida, os escravos africanos se tornaram a maior força de trabalho no País. Sofriam explorações e violências, castigos e torturas.

Santos (2012) afirma que o negro não foi sujeito passivo diante do processo de escravidão, assinalando que a organização negra existe desde esse sistema escravocrata e que as formas de resistência se constituiam por meio da religião, da cultura, da culinária, das danças, das músicas, de fugas e de revoltas urbanas, citando a criação dos quilombos como uma forma de reação diante do sistema de escravidão vigente no Brasil. Entre os anos de 1835 e 1880, surge o movimento pela abolição da escravidão com a Sociedade Brasileira contra a Escravidão. Salles (2011) aponta que a partir da década de 1860 começou a ser delineado um movimento abolicionista no Brasil. A proibição do tráfico em 1850, a criação da Lei do Ventre Livre, em 1871, e o surgimento do movimento abolicionista, ocorrido em 1880, são considerados como passos que foram dados na direção da abolição da escravidão. De acordo com Salles (2011), durante a década de 1870 , surgiram sociedades emancipadoras e o partido Republicano, tendo ocorrido diversas revoltas populares. Em 1880, Joaquim Nabuco considerou como urgente a discussão do projeto de abolição, mas foi derrotado na Câmara. Também foi criada, nesse cenário, a Sociedade Brasileira contra a Escravidão, além de terem sido iniciadas Conferências Abolicionistas. Todas essas lutas culminaram na extinção da escravidão, com a criação da Lei Áurea, a Lei Imperial n. 3.353 de 13 de maio de 1888, que foi sancionada pela Princesa Isabel. A lei declarava extinta a escravidão no Brasil (Lei n. ${ }^{\circ} 3.353,1888$ ).

Porém, após a decretação da Lei Áurea, os escravos saíram da dominação dos seus senhores sem educação, documentos, aparato financeiro ou emprego, tendo que buscar formas de sobreviver em uma sociedade segregada. Saíram de uma condição de exploração plenamente aceita e legalizada, recebendo a liberdade oficializada pela assinatura da supracitada lei, sem, entretanto, ter podido exercê-la, uma vez que foram submetidos a novas e inúmeras formas de exploração, sem integração digna na sociedade, contexto que criou a mão de obra marginalizada e inúmeros desempregados e subempregados, o que se relaciona diretamente ao estigma de que os negros são preguiçosos e malandros. Na medida em que é criada uma lei que afirma que esse escravo se torna livre, a sociedade passa a considerar que ele tem, agora, plenas condições de se desenvolver e quando 
isso não acontece o ex-escravo é culpabilizado, sem que o seu processo de exploração seja levado em conta.

A resistência negra continuou existindo após a abolição da escravidão, tendo sido reconfigurada e adotando como foco a luta pela cidadania e pela liberdade instituida (Santos, 2012). Segundo Albuquerque e Filho (2006), diante do crescimento e da organização da comunidade negra, foram sendo criados jornais e meios que pudessem vincular notícias relacionadas às problemáticas desse grupo. Segundo os autores, era vigente, nesse período, a ideia de que o Brasil era de todos, negando a existência do racismo e as suas consequências.

Ao longo do século $X X$ surgiram grupos reconhecidos pelo Estado, como a Frente Negra Brasileira (FNB), que lutavam pela participação dos negros na vida política do País, além de buscarem, com essa inserção, evitar a criação de políticas segregacionistas por parte da elite branca. Outros projetos que lutavam pela população negra foram criados, alguns deles sendo parados durante a ditadura militar, por conta da perseguição. Após a redemocratização do País, na década de 1980 , os movimentos sociais brasileiros passaram a lutar para que o Governo se posicionasse diante das questões de gênero, etnia e raça, trazendo o tema das ações afirmativas para a discussão (Albuquerque \& Filho, 2006).

Diante desse breve histórico, é possivel considerar que o processo de escravidão ao qual os negros foram submetidos no Brasil trouxe uma série de impactos, incluindo castigos físicos, perda de liberdade, igualdade e identidade, além de uma inserção segregada na sociedade. Ademais, é importante considerar que após o decreto da Lei Áurea não houve medidas do Estado para garantir a inclusão de negros e mestiços na sociedade e criou-se a ideia de que havia uma democracia racial no País, noção muitas vezes ainda defendida atualmente.

Mais especificamente sobre as ações afirmativas no Brasil, encontram-se autores que defendem que essas existem desde a época da escravidão, porém eram iniciativas desligadas do Estado. Nunes (2011) cita, por exemplo, os movimentos abolicionistas, as organizações sociais e a Imprensa Alternativa Negra (IAN). O autor refere que durante o Governo Geisel, teve início a política de distensão, periodo no qual muitas organizações sociais iniciaram lutas políticas e quando foi criado o Movimento Negro Unificado Contra a Discriminação Racial (MNUCDR), em 1978, posteriormente denominado Movimento Negro Unificado (MNU).

Moehlecke (2002) contribui com os dados, trazendo que em 1983 o então deputado federal, Abdias Nascimento, propõe uma ação compensatória aos negros, por meio do projeto de Lei n. ${ }^{\circ}$ 1.332, propondo a reserva de $20 \%$ de vagas para mulheres e homens negros na seleção de candidatos ao serviço público. O projeto não foi aprovado e as reivindicações dos movimentos sociais continuaram. Em 1995 surge a primeira política de cotas nacional, quando foi estabelecido que deveria haver uma reserva de $30 \%$ das vagas para mulheres nas candidaturas de todos os partidos politicos. Com relação aos movimentos negros, eles continuaram os esforços em busca de construir propostas voltadas para a população negra, tendo apresentado ao Governo Federal o Programa de Superação do Racismo e da Desigualdade Racial. Esse documento foi entregue ao Presidente da República, Fernando Henrique Cardoso (FHC), em 1995. Também em 1995, o Governo FHC criou o Grupo de Trabalho Interministerial (GTI), visando à criação de projetos com o objetivo de elevar os padrões de vida da população negra brasileira.

O então senador José Sarney criou um projeto que propunha uma reserva de vagas fixas para negros no Supremo Tribunal Federal (STF), no Ministério da Reforma Agrária e no Instituto Rio Branco (Silva, 2003 como citado em Nunes, 2011). Além disso, parlamentares de vários partidos de esquerda, entre eles o Partido dos Trabalhadores (PT), instituiram projetos de cotas para negros nas universidades públicas (Nunes, 2011). Moehlecke (2002) refere que em 1996 foi lançado o Programa Nacional dos Direitos Humanos (PNDH), pela Secretaria de Direitos Humanos, que havia sido criada há pouco tempo e apresentava, entre 
seus objetivos, desenvolver ações afirmativas para o acesso dos negros a diversos setores da educação, construir políticas compensatórias para promover a comunidade negra economicamente e socialmente, entre outras (Decreto n. $\left.{ }^{\circ} 1.904,1996\right)$.

De acordo com Moehlecke (2002), ainda em 1996 houve a realização do seminário "Ações Afirmativas: estratégias anti-discriminatórias?", realizado no Instituto de Pesquisa Econômica Aplicada e o seminário internacional "Multiculturalismo e racismo: o papel da ação afirmativa nos estados democráticos contemporâneos", promovido pelo Ministério da Justiça em Brasilia (Nunes, 2011).

Foi a partir de 2001 que começaram a ser aprovadas políticas de ações afirmativas. Feres Júnior, Daflon e Campos (2012) trazem que em 2002, no seu programa de governo, o então candidato Luís Inácio Lula da Silva apresentava instrumentos de ações afirmativas, como o programa "Brasil sem racismo". Apontam que, após eleito, durante seu governo, Lula sancionou a Lei n. ${ }^{\circ} 10.639$, de 9 de janeiro de 2003, que estabelece a obrigatoriedade do ensino da "História e Cultura Afro-Brasileira" na rede de ensino (Lei n. ${ }^{\circ} 10.639,2003$ ) e foi criada a Secretaria de Politicas de Promoção da Igualdade Racial (Seppir), em 2003. O órgão tinha como objetivo combater o racismo e promover a população negra nos diversos setores sociais, sendo importante ressaltar que foi ocupado, até 2011, por três ministros negros (Nunes, 2011).

Feres Júnior et al. (2012) atentam para o fato de universidades privadas também adotarem medidas de ações afirmativas, como o Programa Universidade para Todos (ProUni), que surgiu em 2004, tendo sido instituído pela Lei n. ${ }^{\circ}$ 11.096, de 13 de janeiro de 2005, como uma iniciativa de Tarso Genro, o então Ministro da Educação, buscando possibilitar que estudantes de baixa renda ocupassem quase 100 mil vagas ociosas nessas instituições. Os autores relatam que o Governo Lula aumentou o número de vagas nas universidades públicas, com o aumento de unidades dessas instituições, e permitiu o acesso de alunos de baixa renda às instituições de Ensino Superior privado, por meio do programa acima mencionado, por exemplo. Também criou o Programa Nacional de Apoio ao Plano de Reestruturação e Expansão das Universidades Federais (Reuni), com o objetivo de incentivar as universidades públicas a aderirem a programas de igualdade de oportunidade. Referem que, ainda durante o governo de Lula, foi aprovada a proposta que diz respeito à Lei Federal $n .^{\circ} 12.288$, de 20 de junho de 2010, conhecida como Estatuto da Igualdade Racial. Entretanto, a proposta foi aprovada com muitas mudanças com relação à original, o que trouxe muitas perdas para o movimento negro. Mais especificamente com relação às cotas para o Ensino Superior, esse Estatuto as retirou, mas deixou como aberta a possibilidade de que viessem a existir. Além disso, o DEM fez um pedido de inconstitucionalidade das cotas para negros e de anulação da regulamentação das terras de quilombos (Nunes, 2011).

No primeiro biênio do Governo Dilma Rousseff, no final de 2012, houve a declaração da constitucionalidade das cotas e do ProUni pelo STF e a lei que torna obrigatória a adoção da ação afirmativa pelas universidades federais foi aprovada. Além disso, em agosto do mesmo ano a presidenta Dilma sancionou a Lei Federal n. ${ }^{\circ}$ 12.711, de 29 agosto de 2012, que "instituiu reserva de $50 \%$ das vagas nas universidades federais do pais, com percentuais para negros e indígenas na proporção da população de cada estado" (Feres Júnior et al., 2012, p. 407).

É importante ressaltar que, em 2015, a Seppir foi incorporada ao Ministério das Mulheres, da Igualdade Racial, da Juventude e dos Direitos Humanos. Porém, em maio de 2016, após o impeachment da Presidenta Dilma, o novo governo declarou extinto o VII - Ministério das Mulheres, da Igualdade Racial, da Juventude e dos Direitos Humanos, por meio da Medida Provisória n. ${ }^{\circ} 726$ (Medida provisória n. ${ }^{\circ} 726$, 2016). A medida representou um retrocesso para as conquistas dessa população.

Pode-se considerar, por meio do acima exposto, que o caminho das ações afirmativas no Brasil tem sido percorrido de maneira lenta e gradual, desde iniciativas tímidas, quando ainda não 
havia o reconhecimento da discriminação racial existente no País, até o reconhecimento dessa realidade. Porém, ainda assim, foram necessários muitos anos para que as políticas de ações afirmativas começassem a ser implementadas pelos governantes. Durante todo esse tempo a discriminação racial continuou e continua existindo no Brasil.

Para finalizar o presente tópico, será retomada a Lei n. ${ }^{\circ}$ 12.711, que dispõe que as instituições federais de Ensino Superior vinculadas ao Ministério da Educação e as instituições federais de ensino técnico de nível médio

Art. $1^{\circ}[\ldots]$ reservarão, em cada concurso seletivo para ingresso nos cursos de graduação, por curso e turno, no minimo 50\% (cinquenta por cento) de suas vagas para estudantes que tenham cursado integralmente o ensino médio em escolas públicas. Parágrafo único. No preenchimento das vagas de que trata o caput deste artigo, 50\% (cinquenta por cento) deverão ser reservados aos estudantes oriundos de familias com renda igual ou inferior a 1,5 salário-mínimo (um salário-mínimo e meio) per capita. Art. $3^{\circ}$ Em cada instituição federal de ensino superior, as vagas de que trata o art. 1을 desta Lei serão preenchidas, por curso e turno, por autodeclarados pretos, pardos e indigenas, em proporção no mínimo igual à de pretos, pardos e indigenas na população da unidade da Federação onde está instalada a instituição, segundo o último censo do Instituto Brasileiro de Geografia e Estatística (IBGE). (Lei n. ${ }^{\circ}$ 12.711, 2012, p. 1)

O Decreto n. ${ }^{\circ}$ 7.824, de 1 de outubro de 2012 , que regulamenta a Lei acima citada, refere que as instituições federais deverão cumprir integralmente a Lei n. ${ }^{\circ} 12.712$ até 30 de agosto de 2016, devendo implementar, a cada ano, pelo menos $25 \%$ da reserva de vagas (Decreto . $^{\circ} 7.824$, 2012). A Universidade Federal do Ceará (UFC) iniciou a oferta de 12,5\% de suas vagas (por curso e turno) para alunos que cursaram o Ensino Médio na rede pública de ensino em 2013 (Universidade Federal do Ceará, 2013). No ano seguinte, 2014, a UFC passou a adotar os 50\% determinados como cota mínima pela Lei das Cotas.

Alguns dados podem ser articulados a essa discussão. A Universidade de Brasilia (UnB), vanguardista na implantação do sistema de cotas no Brasil, confirma que houve ampliação do acesso de pessoas negras ao Ensino Superior com a política de cotas. Em um periodo curto de tempo, apenas cinco anos, algumas diferenças são notadas: em 2012, os autodeclarados negros correspondiam a 29,85\% dos estudantes da instituição, e os brancos eram 33,03\%. Em 2017. 33.53\% dos novos alunos eram negros, enquanto $29,24 \%$ se autodeclaravam como brancos (Associação Nacional dos Dirigentes das Instituições Federais de Ensino Superior, 2018). Com relação a dados nacionais (não foram encontrados dados referentes ao Ceará), o site Agência Brasil (2018) informou que, em 2000, 2,2\% de pessoas negras concluíram o Ensino Superior, enquanto em 2017 esse número passou a ser de 9,3\%. O Instituto Nacional de Estudos e Pesquisas Educacionais Anísio Teixeira (Inep) elaborou o Censo do Ensino Superior, que trouxe o aumento do número de matrículas de estudantes negros em cursos de graduação. Em 2011, 11\% das matrículas foram feitas por alunos pretos ou pardos, enquanto em 2016 esse número subiu para 30\%. Quando o recorte se volta para pessoas negras entre 18 e 24 anos, os dados indicam que em 2005, 5.5\% de pretos ou pardos estavam no Ensino Superior, enquanto em 2015 esse valor passou a ser $12,8 \%$, segundo o IBGE (Agência Brasil, 2017). Apesar dos dados trazerem boas indicações sobre a importância da política de cotas para acesso ao Ensino Superior, devemos lembrar que os negros não estão com indices similares aos de pessoas brancas, pois como traz a notícia vinculada pela página Agência Brasil (2018), a proporção, em 2017, de brancos graduados era de $22 \%$, o que representa mais do que o dobro dos brancos com diploma no ano 2000, quando o índice era de 9,3\%). Com relação ao recorte de idade, entre 18 e 24 anos, em 2015, 26,5\% de brancos estavam na universidade e em 2005 o número já era 17,8\%, sempre mais do que o dobro de negros (Agência Brasil, 2017). Brancos continuam sendo maioria em universidades públicas e privadas, havendo, portanto, um caminho a ser percorrido, tanto com relação a permanências das ações afirmativas no 
âmbito da educação, como outras medidas que visem à diminuição de desigualdades e reparação de injustiças.

A partir desse panorama, surge a pesquisa referida no início desse artigo, onde foi considerado importante investigar se e como a mudança na oferta de vagas para entrada em uma instituição pública federal de Ensino Superior repercute na percepção dos alunos das escolas públicas de Fortaleza, tendo como foco os estudantes negros, uma vez que os nossos estudos são voltados para as questões étnicoraciais. Nosso recorte de estudantes negros foi daqueles que se declaram pretos e pardos, a mesma classificação utilizada pelo IBGE.

\section{Método}

\section{Delineamento e instrumento}

A pesquisa da qual se originou este artigo foi realizada em duas etapas, tendo sido a primeira de caráter exploratório-descritivo, com metodologia quantitativa, e tendo como objetivo mapear o conhecimento dos estudantes sobre as Políticas de Ações Afirmativas, mais especificamente sobre o sistema de cotas para ingresso no Ensino Superior. Nessa etapa inicial, foi aplicado, em 12 escolas públicas de Ensino Médio, um questionário contendo 13 itens objetivos, sendo que três deles, além das opções de respostas sim ou não, pediam uma justificativa para ambas. Para a escolha das escolas participantes, foi realizado um levantamento, junto à Secretaria de Educação do Estado do Ceará (Seduc), de todas as escolas públicas de Ensino Médio de Fortaleza e, por meio de sorteio, foram selecionadas duas escolas em cada regional da cidade, totalizando 12 instituições.

Após a autorização das escolas, houve a aplicação dos questionários, que ocorreu de forma coletiva, de acordo com a disponibilidade das escolas com relação ao dia e horário das aplicações. A segunda etapa da pesquisa se constituiu como uma pesquisa-intervenção, com abordagem qualitativa e participativa (Castro \& Besset, 2008), quando foram realizadas oficinas em uma das escolas que participaram da primeira etapa do estudo.

\section{Participantes}

Os participantes foram selecionados entre os três anos do Ensino Médio, a partir do interesse dos alunos em participar. A aplicação dos questionários resultou em um total de 464 questionários válidos. A amostra caracterizase da seguinte forma: com relação ao sexo, a maioria $(60,5 \%)$ é do sexo feminino e em relação à faixa etária, a maior concentração está entre 14 a 16 anos (53.5\%). Entre os 464 que fizeram o questionário, dois não responderam o item relativo à cor da pele e, dos 462 que responderam, $80,9 \%$ se autodeclararam pardos ou pretos.

\section{Análise dos dados}

As informações obtidas com a aplicação do questionário foram inseridas em um banco de dados construido no software aplicativo Statistical Package for the Social Sciences_(SPSS), onde foram analisadas e, a partir dessas análises, foi realizada a apresentação dos dados para as escolas acerca da compreensão dos estudantes sobre as politicas de ações afirmativas e sobre o sistema de cotas para ingresso no Ensino Superior. Com relação ao estudo monográfico citado no início desse artigo, tal estudo centrouse especificamente na análise de conteúdo das justificativas dadas aos itens 09, 12 e 13, pelos estudantes que participaram da pesquisa original. Esses itens possuiam respostas binárias (Sim ou Não), que deveriam ser marcadas e justificadas pelos sujeitos. As respostas objetivas foram analisadas, por meio do SPSS, em relação à quantidade de respostas positivas e negativas dos sujeitos e interpretadas de acordo com os objetivos da pesquisa original. Já as justificativas, que tratam dos dados qualitativos, tiveram outro tratamento e interpretação baseado na Análise de Conteúdo de Bardin (2004). Esta análise permitiu a organização, codificação e categorização das justificativas, sendo interpretadas na referida monografia, segundo seus propósitos especificos, enquanto, também foram analisadas, com outros objetivos, na pesquisa original. Os itens que foram analisados estão relacionados, particularmente, com as expectativas dos estudantes para entrar 
no Ensino Médio após tomar conhecimento de que todas as universidades públicas federais e institutos técnicos federais deverão adotar uma reserva de vagas para estudantes de escolas públicas (item og); à compreensão dos alunos com relação ao aumento do acesso de estudantes negros às universidades (item 12) e a possiveis mudanças que acreditam poderem ocorrer nos cursos universitários após a implantação do sistema de cotas (item 13).

\section{Procedimentos éticos}

Após o sorteio das escolas, essas foram contatadas para que se averiguasse o interesse das instituições em participar da pesquisa e para a entrega dos Termos de Consentimento Livre e Esclarecidos (TCLEs), no caso dos alunos menores de idade, e os Termos de Assentimento Livre e Esclarecidos, no caso daqueles maiores de idade. Vale ressaltar que a pesquisa foi autorizada pelo Comitê de Ética da UFC e os procedimentos metodológicos seguiram os princípios éticos científicos concernentes a qualquer pesquisa em Psicologia, em especial, envolvendo pessoas. Foi assegurado aos participantes que responderam ao questionário o caráter confidencial e sigiloso das suas identidades.

\section{Resultados e discussão}

Os dados aqui apresentados referem-se a uma sintese dos resultados da primeira etapa da pesquisa e serão relatados, também, os resultados da análise de conteúdo relativa às justificativas das respostas aos itens 09, 12 e 13 do questionário aplicado.

O primeiro aspecto investigado pelo questionário diz respeito às expectativas de futuro dos participantes da pesquisa. Esta categoria foi avaliada pela Escala de Percepção de Oportunidades de Futuro e os resultados indicam que, em todos os itens da escala, os participantes possuem alta expectativa de futuro. Os resultados mais elevados foram encontrados com relação a concluir o Ensino Médio (89\%), ser respeitado na própria comunidade (81\%), ter um emprego que garanta boa qualidade de vida $(78,9 \%)$ e ter uma casa própria (78,2\%). 0 item que recebeu menor nivel de expectativa foi entrar na universidade, com 66,7\%. Esses dados correspondem aos obtidos na aplicação de uma pesquisa anterior, intitulada "Adolescência e juventude: situações de risco e redes de proteção na cidade de Fortaleza", realizada entre 2009 e 2011. Entre os resultados da pesquisa supracitada destacaram-se as baixas expectativas de ingresso no Ensino Superior por parte de adolescentes e jovens das escolas públicas de Fortaleza, não havendo alteração entre os dois estudos.

As questões que abordam conhecimentos dos estudantes acerca das Políticas de Ações Afirmativas e do Sistema de Cotas apresentam resultados negativos em sua maioria, atestando pouco ou mínima informação a respeito, apenas se destacando um item especíico que pergunta sobre o percentual mínimo de 50\% que as universidades públicas são obrigadas a reservar para as cotas sociais e raciais em seu conjunto. Neste item há um aumento de respostas corretas. A equipe analisou este aumento considerando que, antes da aplicação dos questionários, os alunos receberam esclarecimentos sobre o objetivo da pesquisa e sobre o sistema de cotas, ocasião em que essa informação sobre a porcentagem de vagas era repassada aos estudantes.

Com relação às expectativas de futuro, como citado anteriormente, a "expectativa de entrar na universidade" continua sendo o aspecto de menor índice positivo, assim como foi constatado em pesquisa anterior. Este resultado contraria a hipótese principal do estudo de que haveria mudanças positivas quanto às expectativas dos estudantes sobre seu ingresso no Ensino Superior, considerando que eles deveriam estar informados com relação às políticas de ações afirmativas, em particular, sobre a politica de cotas. Pode-se atribuir como fator influenciador para esse resultado os indicadores dos itens sobre conhecimento acerca do sistema de cotas, pois esses itens revelam a falta de informação dos estudantes do Ensino Médio público a respeito das políticas de ações afirmativas e do Sistema de Cotas, em particular. Portanto, sem um 
conhecimento mais amplo sobre essas políticas, torna-se compreensivel que se mantenham as mesmas porcentagens acerca da perspectiva que os estudantes têm sobre seu ingresso na universidade, já que para eles não houve alteração na forma desse ingresso.

No que se refere aos itens 09, 12 e 13 do questionário, que possuiam respostas objetivas e justificativas abertas, é importante ressaltar que muitos estudantes não responderam ao que estava sendo perguntado na questão, por isso foram consideradas as respostas que se relacionavam com os enunciados. Para situar as referidas questões, aparece um cabeçalho com o seguinte enunciado: "Após tomar conhecimento de que todas as universidades públicas federais e os institutos técnicos federais deverão adotar uma reserva de vagas para estudantes de escolas públicas, entre eles, negros pardos e indígenas, responda as seguintes questões". Segue-se o item 09, que pergunta se esta informação acima muda o interesse e a expectativa do aluno sobre a possibilidade de entrar na universidade, ao que 251 respondentes afirmaram que "Sim", enquanto 203 responderam que "Não".

A análise das justificativas fornecidas pelos participantes ao item og trouxe que, das 251 respostas positivas, 108 foram justificadas afirmando-se que há uma mudança de interesse e expectativa, pois a implantação do sistema de cotas traz um aumento de oportunidades para os estudantes negros de escolas públicas, colocados, em algumas dessas respostas, como desfavorecidos socialmente. Em seguida, aparecem 34 justificativas que consideram que o sistema funciona como incentivo para que os estudantes busquem o acesso ao Ensino Superior. Com relação às justificativas fornecidas por aqueles participantes que responderam "Não" ao item 09, 39 estudantes afirmaram que não há mudança de interesse e expectativa, pois já objetivavam ingressar no Ensino Superior antes da implementação do sistema de cotas, enquanto 21 justificaram que se consideram capazes de ingressar em uma universidade independentemente da existência do sistema de cotas e, por conta disso, não há mudança no interesse e na expectativa.

O item 12 questiona se, na visão dos participantes, o sistema de cotas contribui para aumentar o acesso de negros à universidade. A esse item, 407 participantes responderam positivamente, enquanto somente 42 afirmaram não considerar haver aumento no acesso. Aanálise das justificativas fornecidas pelos participantes ao item 12 trouxe que, das 407 respostas positivas, 182 referem que há o aumento de acesso desses sujeitos ao Ensino Superior, pois o sistema de cotas aumenta a oportunidade de ingresso na universidade, mas sem explicação de como ocorre esse aumento de oportunidade. Dentro dessas 182 justificativas, 54 justificativas apontam que haverá o aumento de acesso, pois o sistema contribui com a diminuição do preconceito, funcionando como apoio aos jovens pretos e pardos. Em seguida, 15 delas trazem a consideração de que esse aumento ocorre por conta da reserva de vagas que há por meio do sistema de cotas. Com relação às justificativas daqueles que afirmaram não considerar que há um aumento de acesso

de pretos e pardos à universidade, destacamse 19 delas que afirmam que o conhecimento e esforço individual permitem o acesso, e não o sistema de cotas. Também nesse item irão aparecer destaques, cujas análises estão adiante, na discussão relacionando os três itens.

O item 13 pergunta se os estudantes consideram que o sistema de cotas trará mudanças para os cursos universitários. Foi observado que 326 respondentes consideram que haverá mudanças, enquanto 122 afirmam que não haverá. O item 13 foi o que os estudantes tiveram mais dificuldade em responder especificamente ao que a questão estava buscando saber. As justificativas se apresentaram da seguinte forma: dos 326 participantes que responderam positivamente ao item, 70 consideram que haverá mudanças nos cursos por conta do aumento de oportunidades para o acesso ao Ensino Superior; 28 justificativas trazem que haverá maior diversidade nos cursos e 16 apontam que haverá diminuição do preconceito, com maior igualdade entre os 
alunos. Com relação àqueles que responderam negativamente, 42 apenas afirmaram que nada irá mudar nos cursos; seis (6) das justificativas trazem que as pessoas que irão ingressar não trarão nenhuma mudança, enquanto cinco (5) afirmam que a mudança será apenas com relação ao número de alunos e três (03) pontuam que a mudança dirá respeito à cor dos alunos que ingressarão, e não aos cursos universitários.

A partir da exposição das justificativas que mais aparecem nos três itens analisados para esse estudo, deve-se atentar para o fato de que, nas três questões, as justificativas mais recorrentes se referem ao aumento de oportunidade trazido pelo sistema de cotas, o que mostra que esses estudantes estão, em alguma medida, considerando que há maiores possibilidades de ingresso no ensino superior.

Porém, para o aprofundamento da discussão, serão destacadas as respostas que apontam para o sistema de cotas como uma forma de preconceito e aquelas que afirmam que, para garantir o acesso ao Ensino Superior, é necessário apenas o conhecimento e esforço individual, o que expressa a insistência no mérito e na competência individual como chave para se alcançar ascensão social. Para compreender tais perspectivas dos estudantes, é necessário que o olhar seja direcionado para os princípios que regem a atual sociedade, como o individualismo e as relações de exploração entre brancos e negros.

Se buscarmos entender como se constitui a lógica racial do Brasil, a partir dos processos de exploração que violentaram, excluíram e estigmatizaram pessoas negras, podemos pensar sobre como práticas e discursos formam relações de poder que constituem subjetividades. Foucault (2002, 2003 como citado em Maia \& Zamora, 2018) explicam que a história constitui o sujeito de conhecimento, ou seja, esses sujeitos são produzidos nos discursos correspondentes à sua inserção histórica e cultural. Destaca-se, nessa discussão, a ideologia do branqueamento que marca a história do Brasil com relação às pessoas negras e brancas, principalmente, após o periodo colonial. Essa ideologia é perpassada pela miscigenação da população, que concorre para a construção do mito da democracia racial, que por sua vez tem o branco como referência, portanto, o negro para ser aceito socialmente deve negar a sua negritude, seus corpos e suas culturas, e assumir o ideal de branquitude a ser atingido (Carone, 2002). Maia e Zamora (2018) afirmam que no início do século $X X$, quando essa política de branqueamento começou a ser institucionalizada, a população negra tentava se inserir socialmente por meio de alisamento do cabelo das mulheres negras, o embranquecimento da cultura, de hábitos, da linguagem, de vestimentas etc. Essa ideologia do branqueamento vem legitimando, ao longo do tempo, o lugar de exclusão do negro, por um lado, e de supremacia do branco, por outro, produzindo subjetividades marcadas pelas desigualdades sociais e pela invisibilidade do racismo como gerador dessas desigualdades.

É importante pensarmos sobre os efeitos desse processo nas subjetividades das pessoas negras que vivem no atual contexto sócio-histórico. O branqueamento e o mito da democracia racial podem ser articulados a essa visão apresentada por alguns jovens que responderam à pesquisa, considerando que o sistema de cotas é uma forma de preconceito e que se deve entrar na universidade por esforço e mérito próprios. Uma vez que existe um processo histórico que destina ao negro o lugar de margem e que assevera que ao branco pertence o lugar de supremacia, além de afirmar que não existem desigualdades raciais no Brasil, as violências, estigmatizações e exclusões do negro são mascaradas e a política de cotas deixa de ser vista como uma política necessária e reparadora diante da construção histórica do Brasil, que se deu a partir da exploração de negros, e passa a ser vista como privilégio do negro em detrimento do branco.

Em uma das respostas encontrada no item og o respondente afirmou que não houve mudança de interesse ou expectativa sobre a possibilidade de entrar na universidade, pois entrar no Ensino Superior por meio das cotas raciais significa que não está entrando por conta dos seus conhecimentos. 
Pensando sobre a construção de tais perspectivas para os jovens negros participantes do estudo, apontamos para a forma de construção da subjetividade. Guatarri (1986 como citado em Soares \& Miranda, 2009) traz uma perspectiva de subjetividade enquanto produção, relacionada à singularidade dos individuos e também à diversidade, à multiplicidade de modos de ser e dos múltiplos agenciamentos de subjetivação. O discurso meritocrático socialmente construido se articula à essa subjetividade produzida e apresentada por alguns jovens, na medida em que sustenta que há igualdade de oportunidades para todas as pessoas, que todas são capazes de alcançar o que desejam com esforço e dedicação, sejam elas brancas ou negras, mas obnubila a desigualdade social, educacional e econômica, resultante, não apenas, mas também, das políticas segregacionistas.

Outro participante afirma que há mudança de expectativa, pois considera que terá vantagens por conta da cor de sua pele. Esse tipo de resposta se vincula também à ideia de que o sistema de cotas se constitui como uma forma de discriminação, pois consideraria os sujeitos negros inferiores, sem capacidade para concorrer com os alunos que estudam em escolas particulares. Essas justificativas se articulam com muitos argumentos difundidos pela sociedade civil com relação à política de cotas: de que se deve entrar na universidade por mérito, de que as cotas trariam desvantagens ao grupo de pessoas brancas, que se preparam e se dedicam por anos para entrar em uma universidade pública, de que ao se utilizar uma reserva de vagas para pessoas negras, essas pessoas estariam sendo postas como inferiores, de que o racismo iria ser acirrado por conta das políticas de cotas, entre tantas outras ideias equivocadas. Para alguns jovens participantes da pesquisa, portanto, essa política está sendo considerada como privilégio sobre pessoas brancas, e não como forma de alcançar uma igualdade de oportunidades que vem sendo negada há séculos na história do Brasil. Essas ideias difundidas socialmente fazem esses estudantes desconsiderarem os processos históricos e olharem para si mesmos como responsáveis por diminuir as vagas de outros estudantes de maneira injusta. Apesar dessas considerações contrárias ao sistema de cotas, estudiosos da área trazem outras reflexões possiveis. Gomes (2001, p. 6-7 como citado em Santos, Cavalleiro, Barbosa, \& Ribeiro, 2008, p. 916), traz o que entende por politicas de ações afirmativas, que seriam políticas públicas e privadas do Estado, de entes vinculados a ele, ou por instituições privadas, que têm como objetivo combater discriminações culturais e estruturais que estão enraizadas socialmente. Essas politicas seriam voltadas para o princípio da igualdade material, presente na constituição, visando concretizar tal principio, e à neutralização das inúmeras e múltiplas formas de discriminação.

Santos et al. (2008) apontam que o Brasil foi construído de forma desigual e injusta, tendo sido fundado a partir da escravidão e do racismo, que levaram à exclusão da população negra, gerando niveis socioeconômicos bastante desiguais. Consideram que a educação formal e de qualidade, nos diversos niveis de ensino, precisa ser garantida como direito de todos os grupos sociorraciais, e a politica de cotas aparece como uma das medidas possiveis para superar as injustiças históricas entre estudantes negros e brancos e de escolas públicas e privadas. Além disso, é importante considerar que essa política pode permitir aos negros formação profissional que favoreça oportunidades de acesso a trabalho qualificado, contribuindo para a diminuição das desigualdades sociorraciais no Brasil.

Gregori e Veronese (2018) trazem uma reflexão sobre algumas questões que se articulam às juventudes, como a questão racial, propondo discussões interseccionais sobre o tema. $O$ Atlas da Violência de 2018 (Instituto de Pesquisa Econômica Aplicada \& Fórum Brasileiro de Segurança Pública, 2018), trazem dados que nos ajudam a pensar sobre a intersecção de que falam as autoras: em 2016 a taxa de homicidios de pessoas negras foi duas vezes e meia superior a de não negras ( $16,0 \%$ contra 40,2\%). Entre 2006 e 2016, a taxa de homicídios de negros cresceu 
$23,1 \%$, enquanto a taxa entre os não negros teve uma redução de 6,8\% no mesmo período. Mais especificamente com relação à juventude, em 2015, o Índice de Vulnerabilidade Juvenil à Violência indicou que o risco de um jovem negro ser vítima de homicídio no Brasil é 2,7 vezes maior que o de um jovem branco. Na análise de 5.896 boletins de ocorrência sobre mortes decorrentes de intervenções policiais entre 2015 e 2016, realizada pelo Anuário Brasileiro de Segurança Pública, descontando as vítimas cuja informação de raça/cor não estava disponível, foi identificado que $76,2 \%$ das vítimas de atuação da polícia são negras.

Como asseveram Gregori e Veronese (2018), as análises de documentos como o Mapa da Violência de 2014 permitem compreender que as violências que se relacionam a crimes estão, em maior grau, associadas ao público juvenil negro (acrescentando-se também pobres e moradores de comunidades segregadas). Outra informação que as autoras fornecem diz respeito às mulheres jovens negras serem mais atingidas por violências domésticas e intrafamiliares. É importante que pensemos sobre a interconexão entre as desigualdades, que não se trata apenas de somar diferentes formas de opressão (Gregori $\&$ Veronese, 2018), mas sim de pensar como a juventude negra, atravessada por um contexto de marginalização e vulnerabilidade, encontra-se mais exposta a riscos e violências, uma vez que se encontra, majoritariamente, em posição desigual com relação à juventude branca, quando se trata de acesso à educação, à saúde, à cultura, aos bens e serviços e à condição socioeconômica justa. O Estatuto da Criança e do Adolescente (Brasil, 1990) estabelece como dever do Estado, da familia e da sociedade a garantia de direitos de crianças e adolescentes e entre esses direitos encontram-se a saúde, a educação, a cultura, o esporte, o lazer, a profissionalização, a proteção, entre outros. Entretanto, ao se refletir sobre como esses direitos vêm sendo garantidos para a juventude, é nítida a diferença entre os direitos assegurados à juventude branca e à negra. Como apontado, o racismo atravessa a organização societal do Brasil, legitimando um processo histórico de marginalização e vulnerabilização de pessoas negras. Portanto, quando pensamos em juventude, é necessário que esse recorte seja feito, não estamos falando de um grupo homogêneo, é uma juventude que vem tendo direitos negados, por isso se faz importante apoiar e defender politicas que visam a reparar desigualdades e injustiças sociais.

Dessa forma, a partir das considerações acima sobre o que são as ações afirmativas, considerase essencial que o Estado apoie e incentive o sistema de cotas para o Ensino Superior, pois essa politica tem como objetivo proporcionar igualdade de oportunidades, repor direitos que continuam sendo violados e retirados da população negra.

\section{Considerações finais}

Percebe-se, através das análises das justificativas dos participantes, que o sistema de cotas aparece como oportunidade para ingresso no Ensino Superior, o que aumenta as expectativas dos estudantes para obter o acesso à universidade, apesar de ainda serem encontradas opiniões divergentes com relação a essa política. Observou-se, de modo geral, um reduzido conhecimento das Políticas de Ações Afirmativas, especialmente das cotas para entrada no Ensino Superior. Ressalta-se que, desde o momento inicial de inserção nas escolas, a equipe buscou fornecer elementos para que os estudantes se sentissem motivados a buscar maiores informações a respeito.

O aspecto da ausência de conhecimentos sobre oportunidades que se abrem para estudantes da rede pública de ensino levanta alguns pontos que merecem ser destacados: 1) é revelador das lacunas ainda muito presentes na educação formal dirigida às crianças e aos jovens que estão na escola pública; 2) aponta para a urgência de ampliar investimentos públicos voltados para a qualidade de ensino em todos os níveis educacionais e, em especial, no Ensino Médio; 3) evidencia a importância do ensino da história e cultura africana e afrobrasileira; 
e 4) aponta para a necessidade de aprofundar a investigação com propostas de abordagens metodológicas qualitativas e participativas.

Ressalta-se, ainda, que a existência de opiniões divergentes sobre o sistema de cotas decorre de mitos como a democracia racial e de uma visão equivocada da história da abolição da escravidão como um processo de superação das desigualdades sociais entre brancos e negros, quando a libertação dos escravos não foi acompanhada de uma política de promoção de condições de trabalho e de sobrevivência digna para essa população. Isso contribui para que não se perceba a divida histórica com a população negra e a necessidade de políticas afirmativas como reparadoras e não como privilégio.

É importante destacar que os avanços conquistados com as políticas de ações afirmativas, especialmente o sistema de cotas, correm o risco de serem paralisados ou até mesmo regredidos. Essa constatação se dá diante do atual governo brasileiro, pois a figura política eleita como Presidente da República nas eleições ocorridas em 2018 emitiu, em mais de uma situação, declarações racistas e discriminatórias com relação às pessoas negras, além de se posicionar publicamente contrário ao sistema de cotas. Há que fazer frente e reagir a esse retrocesso, com mobilizações coletivas e lutas para assegurar o estado democrático de direito e a continuidade do processo de visibilização e superação do racismo no nosso País.

Como referem Gregori e Veronese (2018), as políticas públicas se apresentam como essenciais para que o caminho na direção da diminuição das desigualdades que se relacionam de forma interseccional possa continuar existindo. Essas políticas podem fornecer mecanismos para que os jovens desenvolvam suas formações e se insiram socialmente. Nesse cenário, a política de cotas para entrada no Ensino Superior se apresenta como importante medida no contexto brasileiro, mas assevera-se a necessidade de ações diversas e plurais que se direcionem à saúde, à cultura, ao lazer, entre outros aspectos fundamentos ao desenvolvimento e proteção dos jovens.

\section{Referências}

Agência Brasil. (2018). Cotas foram revolução silenciosa no Brasil, afirma especialista IPágina de noticiasl. Recuperado de http://agenciabrasil.ebc.com. br/educacao/noticia/2018-05/cotas-foram-revolucao-silenciosa-no-brasil-afirma-especialista. https:// doi.org/10.29388/978-85-53111-28-2-0-f.63-78

Agência Brasil (2017). Percentual de negros nas universidades dobra em 10 anos [Página de noticias]. Recuperado de https://guiadoestudante.abril. com.br/universidades/percentual-de-negros-nas-universidades-dobra-em-10-anos/. https://doi. org/10.26563/dobras.vgi20.475

Albuquerque, W. R., \& Filho, W. F. (2006). Uma história do negro no Brasil. Salvador, BA: Centro de Estudos Afro-Orientais; Brasilia, DF: Fundação Cultural Palmares, 2006.

Associação Nacional dos Dirigentes das Instituições Federais de Ensino Superior. (2018). UnB - Perfil do estudante mostra aumento de alunos negros e de baixa renda [Página de notícias]. Recuperado de http://www.andifes.org.br/unb-perfil-estudante-mostra-aumento-de-alunos-negros-e-de-baixa-renda/. https://doi.org/10.11606/d.12.2008. tde-23012009-125402 Bardin, L. (2004). Análise de conteúdo. (3a. ed.) Lisboa: Edições 70.

Carone, I. (2002). Breve histórico de uma pesquisa psicossocial sobre a questão racial brasileira. In I. Carone \& M. A. S. Bento. (Orgs.), Psicologia social do racismo: estudos sobre branquitude e branqueamento no Brasil (p. 13-23). Petrópolis, RJ: Vozes.

Conselho Federal de Psicologia. (2017). Relações Raciais: Referências Técnicas para atuação de psicólogas/os. Brasilia, DF: CFP.

Lei n 8.069, de 13 de julho de 1990. (1990). Dispõe sobre o Estatuto da Criança e do Adolescente e dá outras providências. Brasilia, DF. Recuperado de http://Www.planalto.gov.br/ccivil_03/ LEIS/L8069.htm. https://doi.org/10.1590/0034716719730005000016

Castro, L. R., \& Besset, V. L. (2008). Pesquisa-Intervenção na Infância e Juventude: construindo caminhos. In Castro, L. R., \& Besset, V. L. (Orgs.). Pesquisa-Intervenção na Infância e Juventude ( $p$. o9-14). Rio de Janeiro, RJ: NAU/FAPERJ. https://doi. org/10.17771/pucrio.acad.4304

Decreto $n^{\circ}$ 1.904, de 13 de maio de 1996. (1996). Institui o programa nacional de direitos humanos - PNDH. Brasilia, DF, Recuperado de http://Www. planalto.gov.br/ccivil_03/decreto/d1904.htm.

Decreto n. $^{\circ} 7.824$, de 11 de outubro de 2012. (2012). Regulamenta a Lei n' 12.711 , de 29 de agosto de 2012, que dispõe sobre o ingresso nas universidades federais e nas instituições federais de ensino técnico de nivel médio. Brasilia, DF. Recuperado de http://www.planalto.gov.br/ccivil_03/_ato20112014/2012/Decreto/D7824.htm. https://doi. org/10.24824/978854442280.9 
Feres Júnior, J., Daflon, V. T., \& Campos, L. A. (2012). Ação afirmativa, raça e racismo: uma análise das ações de inclusão racial nos mandatos de Lula e Dilma. Revista de C. Humanas, 12(2), 399-414. Recuperado de http://wwww.cch.ufv.br/revista/pdfs/ vol12/artigo8vol12-2.pdf https://doi.org/10.21878/ compolitica.2012.2.2.69

Gregori, J. \& Veronese, C. (2018). Juventudes, violências e interseccionalidades no Brasil: reflexões a partir do Estatuto da Juventude. Interfaces cientificas - humanas e sociais, 7(1), 71-82. https://doi. org/10.17564/2316-3801.2018v7n1p71-82

Instituto de Pesquisa Econômica Aplicada \& Fórum Brasileiro de Segurança Pública. (2018). Atlas da Violência 2018. Recuperado de http://www.ipea.gov. br/portal/images/stories/PDFs/relatorio_institucional/180604_atlas_da_violencia_2018.pdf

Lei . $^{\circ}$ 12.711, de 29 de agosto de 2012. (2012). Dispõe sobre o ingresso nas universidades federais e nas instituições federais de ensino técnico de nivel médio e dá outras providências. Brasília, DF Recuperado de http://www.planalto.gov.br/ccivil_03/_ato2011-2014/2012/lei/l12711.htm. https:// doi.org/10.24824/978854442280.9

ei No 3.353, de 13 de maio de 1888. (1988). Declara extinta a escravidão no Brasil. Rio de Janeiro, RJ. Recuperado de www.planalto.gov.br/ccivil_03/Leis/ LIM/LIM3353.htm.

Lei n. ${ }^{\circ}$ 10.639, de 9 de janeiro de 2003. (2003). Altera a Lei $n^{\circ}$ 9.394, de 20 de dezembro de 1996 que estabelece as diretrizes e bases da educação nacional, para incluir no currículo oficial da Rede de Ensino a obrigatoriedade da temática História e Cultura Afro-Brasileira" e dá outras providências. Brasilia, DF. Recuperado de http://www.planalto. gov.br/ccivil_03/leis/2003/L10.639.htm. https://doi. org/10.31418/2177-2770.2018.v10.noo.p820-835

Libório, R. M. C., \& Koller, S. H. (Orgs.). (2009). Adolescência e Juventude: risco e proteção na realidade brasileira. São Paulo, SP: Casa do Psicólogo.

Maia, K. S. \& Zamora, M. H. N. (2018). O Brasil e a lógica racial: do branqueamento à produção de subjetividade do racismo. Psic. Clin., 30(2), 265-286. Recuperado de http://pepsic.bvsalud.org/pdf/pc/v30n2/05.pdf.

Medida provisória n. 726, de 12 de maio de 2016. (2016). Altera e revoga dispositivos da Lei $n^{\circ} 10.683$, de 28 de maio de 2003, que dispõe sobre a organização da Presidência da República e dos Ministérios. Brasília, DF. Recuperado de http://www.planalto.gov.br/ ccivil_03/_Ato2015-2018/2016/Mpv/mpv726.htm https://doi.org/10.1590/0034-716719750003000001

Moehlecke, S. (2002). Ação afirmativa: história e debates no Brasil. Cadernos de Pesquisa, 117, 197-217. https://doi.org/10.1590/s0100-15742002000300011 Monteiro, P. F. C. (2012). Discussão acerca da eficácia da Lei Áurea. Meritum, 7(1), 355-387. Recuperado de http://www.fumec.br/revistas/meritum/article/ view/1208/829.)
Nunes, A. A. C. (2011). O sistema de cotas para negros na universidade federal do maranhão: uma politica de ação afirmativa para a população afromaranhense. (Tese de Doutorado). Faculdade de Filosofia e Ciências, Universidade Estadual Paulista Júlio de Mesquita Filho, Marilia. Recuperado de https://repositorio.unesp.br/bitstream/handle/11449/104812/ nunes_aac_dr_mar.pdf?sequence=1\&isAllowed =y. https://doi.org/10.18362/bjta.v6.i2.15

Salles, R. (2011). Abolição no Brasil: resistência escrava, intelectuais e politica (1870-1888). Revista de Índias, 71(251), 259-284. https://doi.org/10.3989/ revindias.2011.010

Santos, A. V. (2012). Os efeitos de sentidos nos dizeres de professores soteropolitanos sobre a lei 10.639/03. (Dissertação de Mestrado). Departamento de Ciências Humanas, Universidade do Estado da Bahia, Salvador. https://doi.org/10.7594/revbio.19.01.01

Santos, S. A., Cavalleiro, E., Barbosa, M. I. S., \& Ribeiro, M. (2008). Ações afirmativas: polêmicas e possibilidades sobre igualdade racial e o papel do Estado. Estudos feministas, 16(3), 913- 929. https://doi. org/10.1590/s0104-026×2008000300012

Soares, L. B. \& Miranda, L. L. (2009). Produzir subjetividades: o que significa? Estud. pesqui. psicol., 9(2), 408-424.

Universidade Federal do Ceará. (2013). UFC adotará $50 \%$ de cotas já a partir de 2014, decide Conselho Universitário. Recuperado de http://www.ufc.br/ noticias/noticias-de-2013/4207-ufc-adotara-50-de-cotas-ja-a-partir-de-2014-decide-conselho-universitario. https://doi.org/10.20873/uft. 2179-3948.2018v9n3p384

\section{Endereço para correspondência:}

Livia Lima Gurgel (Rua Romeu Martins, n 169, Fortaleza, Ceará, CEP 60420-720. (85) 996525735, livialgurgel@ gmail.com)

\section{Autor I}

Nome: Livia Lima Gurgel

E-mail: livialgurgel@gmail.com

Titulação Acadêmica: Mestrado

Afiliação Institucional: GEPSID/Universidade do Estado do Rio de Janeiro (UERJ)

\section{Autor II}

Nome: Veriana de Fátima Rodrigues Colaço

Titulação Acadêmica: Doutorado

Afiliação Institucional: Universidade Federal do Ceará (UFC) 